\title{
ESTUDO DA REMOÇÃO DE GLICEROL NA ETAPA DE PURIFICAÇÃO DE BIODIESEL UTILIZANDO CARVÃO VEGETAL COMO ADSORVENTE
}

\author{
V. B. PAIVA ${ }^{1}$, S. MASUDA ${ }^{1}$, F. N. de PROENÇA ${ }^{1}$, M. B. GHELLER ${ }^{1}$, M. C. S. GOMES ${ }^{1}$ \\ ${ }^{1}$ Universidade Tecnológica Federal do Paraná, Departamento de Engenharia Química \\ E-mail para contato: vassula@alunos.utfpr.edu.br
}

\begin{abstract}
RESUMO - O biodiesel é um combustível biodegradável, obtido pela reação de transesterificação ou esterificação de óleos vegetais. Após a reação, os ésteres produzidos devem ser submetidos a etapas de purificação para a remoção de glicerol livre e outros contaminantes. Os processos comumente utilizados na etapa de purificação utilizam lavagens com água e resultam na geração de grandes quantidades de efluentes, que devem ser tratados e eliminados. No presente trabalho, o biodiesel foi produzido por transesterificação etílica de óleo de milho neutro por meio de catálise alcalina. Foi avaliada a eficiência da purificação do biodiesel por adsorção utilizando carvão vegetal em comparação com o carvão ativado comercial. Os experimentos foram realizados em batelada e os resultados obtidos demonstraram que, para o adsorvente em estudo, a adsorção pode ser realizada em temperatura ambiente, uma vez que a remoção de glicerol foi significativa, sendo uma alternativa aos processos tradicionais de refino de biodiesel.
\end{abstract}

\section{INTRODUÇÃO}

A geração de gases poluentes pela queima de combustíveis fósseis e, consequentemente, os danos causados ao ambiente, motivaram a busca por fontes alternativas de energia. $\mathrm{O}$ biodiesel é um combustível biodegradável, não tóxico, que possui alto conteúdo energético e escassez de enxofre, sendo uma excelente alternativa ao diesel. É composto por ésteres monoalquílicos de ácidos graxos de cadeia longa, proveniente de óleos vegetais e gordura animal (Manique et al., 2011).

O método mais usual para a produção de biodiesel é pela reação de transesterificação alcalina, em que os triacilglicerois presentes nos óleos e gordura reagem com um álcool (normalmente etanol ou metanol), na presença de um catalisador, produzindo ésteres alquílicos e glicerol como coproduto (Vasques, 2010).

Silva et al (2014), aponta que os contaminantes presentes no biodiesel podem causar danos operacionais e ambientais. Desse modo, para que os ésteres possam ser utilizados como combustível, devem estar de acordo com as especificações determinadas pela Agência Nacional do Petróleo, Gás Natural e Biocombustíveis (ANP). Na remoção destes contaminantes são utilizados métodos de purificação por via úmida ou via seca. 
A purificação por via úmida é um método tradicional, mas que acarreta em desvantagens devido à adição de água, que apesar de possibilitar a remoção de sabões, do catalisador residual e dos traços de glicerol no biodiesel, dificulta o processo pela necessidade de eliminação de umidade, além da geração de efluentes e aumento do custo e tempo na produção segundo Costa (2010).

Como alternativa, pode ser utilizado o método de purificação por via seca, que dispensa o uso da água. Neste processo, o material adsorvente deve possuir como características seletividade, área superficial elevada, resistência mecânica e baixo custo. Além da redução de efluentes, este método de purificação possibilita o aumento da qualidade do biocombustível e a redução do tempo de produção. Atualmente, há adsorventes específicos comercializados para purificação de biodiesel como: carvão ativado, silicato de cálcio, fosfato de magnésio, Magnesol ${ }^{\circledR}$ e as resinas Purolite ${ }^{\circledR}$ PD206 e Amberlite ${ }^{\circledR}$ BD10 Dry (Costa, 2010). Desta forma, o objetivo deste presente trabalho foi avaliar a utilização do carvão de casca de coco como adsorvente para a purificação do biodiesel determinando a melhor condição de processo por meio das curvas cinéticas e isotermas de adsorção.

\section{MATERIAIS E MÉTODOS}

Para a produção do biodiesel, foi utilizado óleo de milho neutro fornecido pela empresa Caramuru (Apucarana, Paraná). As características do óleo foram determinadas de acordo com a metodologia oficial da AOCS, apresentando índice de acidez de 0,43 (mg KOH/g amostra), viscosidade de $31,6\left(\mathrm{~mm} 2 / \mathrm{s}\right.$ a $\left.40^{\circ} \mathrm{C}\right)$ e densidade igual a $0,9146 \mathrm{~g} / \mathrm{mL}$. Também foram utilizados álcool etílico absoluto PA 99,5\% e hidróxido de sódio para a catálise alcalina.

Para a adsorção, foi utilizado o carvão vegetal de casca de coco com granulometria de 20/40 (MESH). Outras características do adsorvente foram determinadas a partir dos métodos de Brunauer-Emmet-Teller (BET) e Barrett-Joyner-Halenda (BJH) tendo como resultados uma área superficial específica de $712,4 \mathrm{~m}^{2} / \mathrm{g}$, volume de poro de $0,0404 \mathrm{~cm}^{3} / \mathrm{g}$ e raio do poro de 20,83 Å. Para fazer uma comparação, foi utilizado o carvão ativado comercial PA em pó.

\subsection{Cinética de Adsorção}

A cinética foi realizada em batelada utilizando uma incubadora shaker na temperatura de $25^{\circ} \mathrm{C}$ e $40^{\circ} \mathrm{C}$. Foram adicionados $2,0 \mathrm{~g}$ de adsorvente em erlenmeyers de $250 \mathrm{~mL}$ contendo $50 \mathrm{~mL}$ de biodiesel e deixados sob agitação de $150 \mathrm{rpm}$ durante o período de 1, 5, 10, 20, 30, $60,90,120,180,240$ e 300 minutos. Após cada um dos períodos de tempo, foi retirado um erlenmeyer e seu conteúdo foi submetido ao processo de filtração a vácuo, para separar o biodiesel do adsorvente. O teor de glicerol livre foi determinado por meio de uma metodologia modificada, baseada no método oficial da AOCS para análise de glicerol livre em óleos e gorduras (Ca 14-56) (Pisarello et al., 2010).

\subsection{Isoterma de Adsorção}

A isoterma também foi realizada em batelada utilizando uma incubadora shaker na temperatura de $25^{\circ} \mathrm{C}$. Neste caso, o adsorvente foi adicionado nas concentrações de 5, 10, 20, $50,100,150,200,300$ e $500 \mathrm{~g} / \mathrm{L}$ em erlenmeyers de $250 \mathrm{~mL}$ contendo $50 \mathrm{~mL}$ de biodiesel e deixados sob agitação de $150 \mathrm{rpm}$ durante o período de 180 minutos. Posteriormente, o 
biodiesel foi separado do adsorvente por filtração a vácuo e o teor de glicerol nas amostras foi determinado.

\section{RESULTADO E DISCUSSÃO}

Ao final da transesterificação, após a separação das fases por decantação, a fase rica em ésteres (biodiesel), apresentou um teor de glicerol livre acima do limite estabelecido para a comercialização (ANP, 2008), que é de 0,02\% em massa. Este resultado evidncia que somente a separação de fases por decantação não é suficiente para purificar o biodiesel, sendo necessária uma etapa posterior para a adequação dos ésteres às especificações exigidas para a comercialização.

A influência da temperatura na remoção de glicerol utilizando a adsorção com o carvão vegetal de casca de coco pode ser verificada na Figura 1. É possível observar, para as duas temperaturas avaliadas, uma tendência de aumento da remoção de glicerol com o aumento do tempo de contato. Porém, o aumento da temperatura de $25^{\circ} \mathrm{C}$ para $40{ }^{\circ} \mathrm{C}$ proporcionou uma redução na capacidade de adsorção de glicerol no carvão. A $25{ }^{\circ} \mathrm{C}$, além de atingir o equilíbrio em um tempo menor, uma remoção maior foi observada em todos os tempos avaliados, que foi maior do que $60 \%$ após 5 minutos de contato.

Figura 1 - Influência do tempo de contato na adsorção de glicerol em temperaturas diferentes

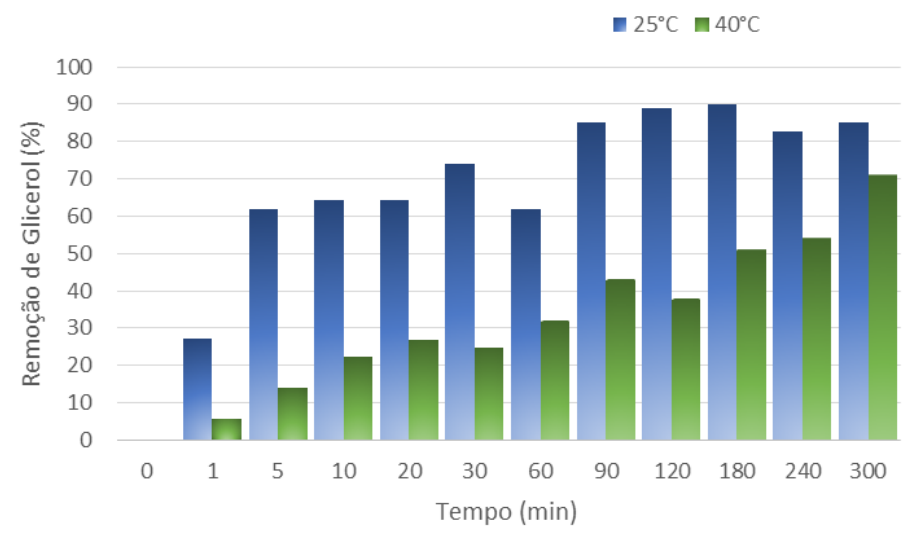

$\mathrm{Na}$ Figura 2 é apresentada a avaliação da variação da quantidade de adsorvente utilizada. Os resultados mostram que a partir da concentração de $20 \mathrm{~g} / \mathrm{L}$ de adsorvente a remoção é superior a 70\%, com exceção de um ponto, sugerindo um desempenho elevado do carvão de casca de coco na purificação do biodiesel.

Figura 2 - Influência da concentração de carvão vegetal na adsorção de glicerol 


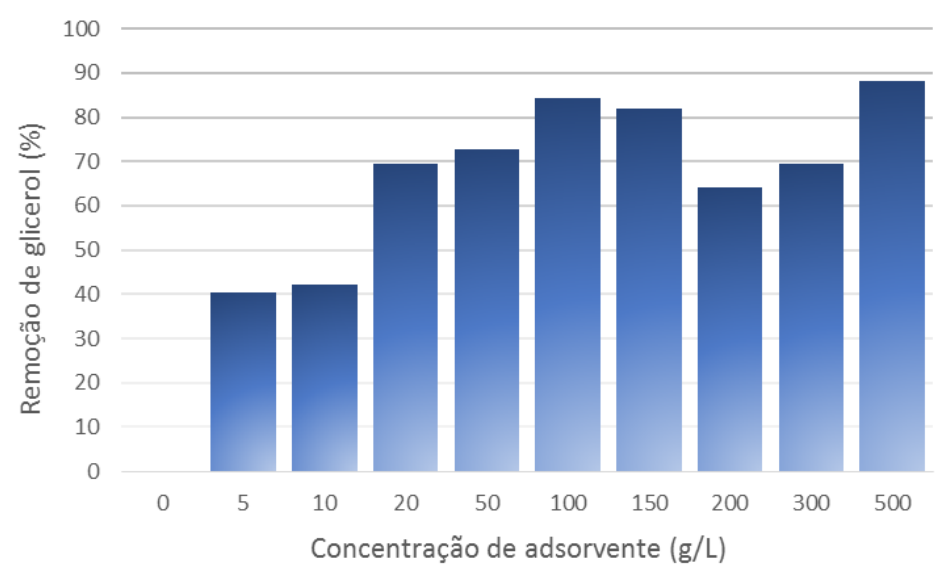

À medida em que se eleva a concentração de adsorvente, é esperada um aumento da remoção de glicerol, uma vez que existe uma maior área para a adsorção, até que seja estabelecido o equilíbrio. No entanto, este comportamento não foi verificado quando foram utilizadas concentrações acima de $100 \mathrm{~g} / \mathrm{L}$. Estes resultados provavelmente foram causados devido à presença de pequenas partículas de carvão que permaneceram presentes na amostra de biodiesel, mesmo após a separação do adsorvente por filtração à vácuo. Estas partículas resultam do atrito que ocorre entre as partículas durante o processo de adsorção. Foi verificado que quanto maior a concentração de adsorvente no biodiesel para a adsorção, maior foi $\mathrm{o}$ atrito e, consequentemente, a geração de partículas finas que tornaram a filtração ineficiente. Provavelmente, estas partículas de carvão que permanecem em solução, após a filtração, retêm glicerol livre.

A presença de adsorvente residual no biodiesel foi evidenciada pela mudança de cor das amostras, conforme apresentado na Figura 3.

Figura 3 - Ensaio de adsorção com diferentes concentrações de adsorvente ( 1 - biodiesel não purificado; 2 -5 g/L; $3-10 \mathrm{~g} / \mathrm{L} ; 4-20 \mathrm{~g} / \mathrm{L} ; 5-50 \mathrm{~g} / \mathrm{L} ; 6-100 \mathrm{~g} / \mathrm{L} ; 7-150 \mathrm{~g} / \mathrm{L} ; 8-200 \mathrm{~g} / \mathrm{L} ; 9$ $-300 \mathrm{~g} / \mathrm{L} ; 10-500 \mathrm{~g} / \mathrm{L}$

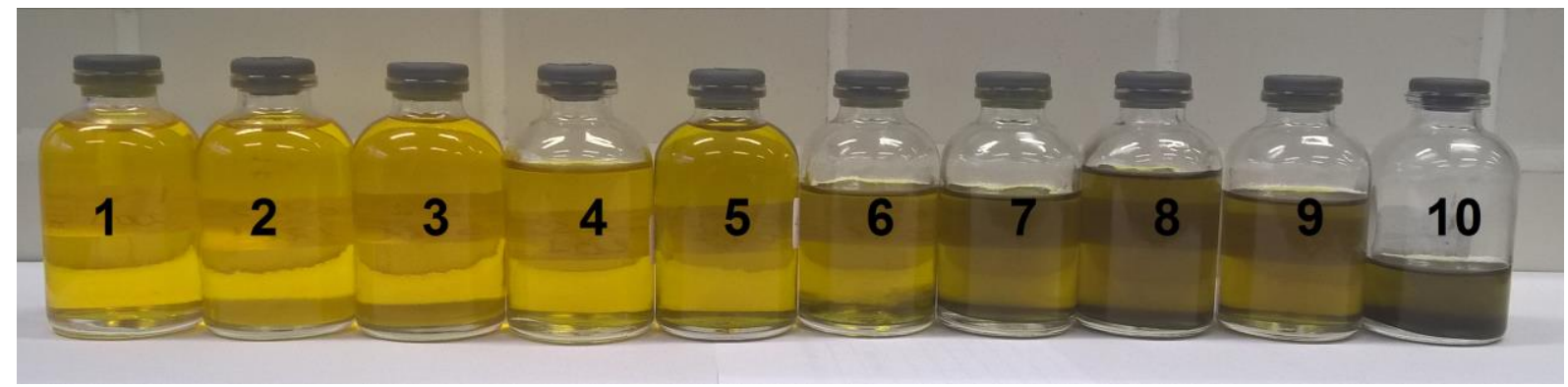

Contudo, mesmo havendo interferência na remoção de glicerol livre e, consequentemente, em sua determinação, os teores de glicerol livre em todas as amostras foram menores do que o valor observado no biodiesel não purificado, conforme a Figura 4, evidenciando que houve remoção. Além disso, é possível observar que mesmo utilizando concentrações baixas, a remoção do glicerol foi significativa, alcançando valores abaixo do máximo permitido quando utilizada a concentração de $100 \mathrm{~g} / \mathrm{L}$ de adsorvente. 
Figura 4 - Influência da concentração de carvão ativado em pó na adsorção de glicerol

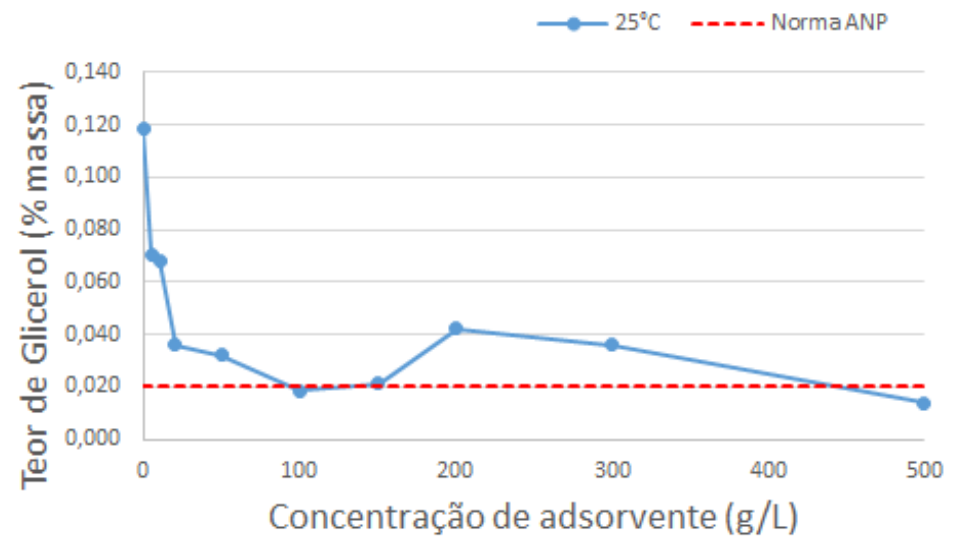

Para que fosse avaliada a influência da granulometria do carvão utilizado na remoção de glicerol, para as condições de filtração a vácuo utilizadas, foram realizados ensaios de adsorção utilizando carvão ativado na forma de pó. Os resultados apresentados na Figura 5 indicam uma maior interferência negativa na separação, que fica mais evidente com o aumento da concentração de adsorvente. O processo de filtração utilizado não foi eficiente na separação do adsorvente após o tempo de contato, de modo que os resultados não seguem uma tendência de remoção, além de haver pontos em que o teor de glicerol é maior que o do biodiesel sem purificação, indicando uma interferência, também, no método de quantificação do glicerol.

Figura 5 - Teor de glicerol pelo teor de adsorvente do carvão ativado

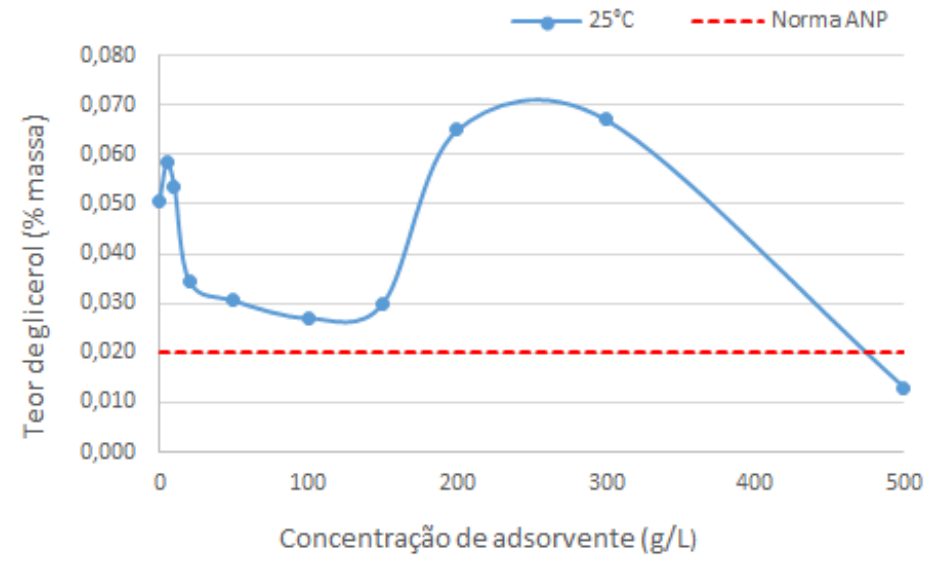

Para diminuir a interferência negativa que as partículas não retidas na filtração causam nos resultados de remoção do glicerol, seria recomendado o uso de uma granulometria com particulados maiores ou um processo de filtração mais eficiente, que evite a passagem das partículas que se desprendem devido ao atrito. Ainda assim, o carvão ativado pode ser empregado na purificação do biodiesel de forma eficiente nas condições de 180 minutos e uma concentração de $100 \mathrm{~g} / \mathrm{L}$, dispensando etapas de lavagens com água. 


\section{CONCLUSÃO}

Os métodos de purificação a seco apresentam-se como alternativa para a redução da quantidade de água utilizada na etapa de purificação do biodiesel. Além disso, o uso de resíduos como adsorventes pode proporcionar a redução de custos no processo. Os resultados obtidos neste trabalho indicam que o adsorvente estudado, carvão vegetal obtido a partir de casca de coco, pode ser empregado na purificação do biodiesel na temperatura ambiente $\left(25^{\circ} \mathrm{C}\right)$, concentração de adsorvente de $100 \mathrm{~g} / \mathrm{L}$ e tempo de 3 horas, para que a adsorção seja eficiente e resulte em um biodiesel dentro das especificações da ANP. Concluiu-se, também, que o tamanho das partículas de adsorvente pode interferir nos processos de determinação dos teores de glicerol livre, mostrando a necessidade de melhoria do método de filtração para a separação do adsorvente do biodiesel purificado.

\section{REFERÊNCIAS}

ANP. Resolução da Agência Nacional de Petróleo, Gás Natural e Biocombustíveis n 7 , de 19 de março de 2008. Disponível em: http://www.udop.com.br/download/legislacao/comercializacao/juridico_legiscalcao/res_7_co mercializacao_biodiesel.pdf > Acesso em: 11 mar. 2017.

COSTA, A. L. Purificação de biodiesel com uso de adsorventes alternativos. Florianópolis, p. 21-78, 2010. Tese (Doutorado) - Universidade Federal de Santa Catarina.

MANIQUE, M. C. et al. Rice husk ash as an adsorbent for purifying biodiesel from waste frying oil. Elsevier, 2011.

PISARELLO, M. L. et al. Volumetric method for free and total glycerin determination in biodiesel, Industrial and Engineering Chemistry Research 49 (2010) 8935-8941.

SILVA, F. H. et al. Purificação de biodiesel por adsorção em carvão ativado. In: CONGRESSO BRASILEIRO DE ENGENHARIA QUÍMICA, 20, 2014, Florianópolis.

VASQUES, E. de C. Adsorção de glicerol, mono e diglicerídeos presentes no biodiesel produzido a partir do óleo de soja. Dissertação (Mestrado) - Programa de Pós-Graduação em Tecnologia de Alimentos, Universidade Federal do Paraná. Curitiba, 2010. 